\title{
Estimation of Plant Biomass by Spectral Reflectance in an East African Grassland
}

\author{
THOMAS W. BOUTTON AND LARRY L. TIESZEN
}

\section{Abstract}

Canopy spectral reflectance measurements at 0.800 and 0.675 $\mu \mathrm{m}$ were made in a grassland in Masai Mara Game Reserve, Kenya. The reflectance ratio $(0.800 / 0.675 \mu \mathrm{m})$ was shown to be a reliable predictor of green biomass, accounting for $70 \%$ of the variance in green biomass values. Significant error in the biomass estimates was shown to be due to plots which contained less than $30 \%$ of the total vegetation in the live condition. Estimation error tended to increase when time of sampling departed from the interval of 1000 to 1400 hours, although this trend was not statistically significant. We conclude that the spectral reflectance technique can provide reliable estimates of plant biomass in grassland ecosystems where the proportion of live:total vegetation exceeds $30 \%$.

The distribution and abundance of plant biomass in space and time are important properties of rangeland ecosystems. However, the accurate measurement of vegetative biomass by traditional clipping and weighing is a time-consuming and labor-intensive process. As a result, many indirect methods of monitoring plant community biomass have been developed with varying degrees of success. Some of these methods have been reviewed by Tucker (1980).

One of the more promising methods of biomass estimation involves the measurement of canopy spectral reflectance in the red $(0.600-0.700 \mu \mathrm{m})$ and the near infrared $(0.750-1.00 \mu \mathrm{m})$ wavelengths. The red wavelength region is measured because chlorophyll has an absorption maximum at $0.675 \mu \mathrm{m}$, whereas green biomass is highly reflective in the near infrared region (Tucker 1977). The reflectance at $0.800 \mu \mathrm{m}$ divided by the reflectance at $0.675 \mu \mathrm{m}$ yields a ratio which is sensitive to the amount of green biomass present in a given area. Several studies have reported success using spectral reflectance techniques to predict green biomass in rangeland ecosystems (Pearson et al. 1976; McNaughton 1976, 1979; Waller et al. 1981). The purpose of this investigation was to provide a further test of the relationship between standing green biomass and the reflectance ratio and to assess the feasibility of using this technique to monitor rangeland vegetation dynamics.

\section{Study Area and Methods}

The study was carried out in the $1673 \mathrm{~km}^{2}$ Masai Mara Game Reserve in southwestern Kenya. This park lies between 1 and 2 degrees $S$ latitude and 35 and 36 degrees $E$ longitude at an average elevation of $1600 \mathrm{~m}$ and is the northernmost portion of the Serengeti ecosystem. Mean annual temperature from 1975-1980 was $20.5^{\circ} \mathrm{C}$ with little monthly variation, while mean annual precipita-

\footnotetext{
The authors are assistant professor and professor, respectively, in the Biology Department, Augustana College, Sioux Falls, S. Dak. 57197.

This work was supported by research grants from the U.S. National Science Foundation (DEB-78-19552) and the William and Flora Hewlett Foundation of Research Corporation. Helmut Epp of the Kenya Rangeland Ecological Monitoring Unit (KREMU) provided the radiometer. Dr. S.K. Imbamba, Department of Botany, University of Nairobi, provided assistance in many ways. Janet Boutton, Bret Hesla, and Athanas Imbwaka assisted in the lab and field work. Jeff Dixon helped with computer analyses. Cheryl Holzapfel typed the manuscript,and Becky Rossing prepared the figures. We especially thank the Government of Kenya and its Ministry of Environment and Natural Resources for research clearance and use of the Masai Mara Wild life Research Station.

Manuscript received August 12, 1981
}

tion during this same period was $1034 \mathrm{~mm}$. Soils are mainly of volcanic origin and range from brown sandy loams to black heavy clays.

Fourteen plant communities have been identified within Masai Mara (Taiti 1973), but most of the reserve consists of open or lightly wooded grasslands dominated by the grass Themeda triandra Forsk, (red oat grass). Peak values of standing crop vegetation (live plus dead) occur in June shortly after the rainy season and range up to $700 \mathrm{~g}^{-2} \mathrm{~m}^{-2}$.

The diversity, density, and biomass of wild herbivores in this ecosystem are extremely high throughout the year. During 1978-1979, average monthly biomass of wild herbivores in our study areas was 19.3 metric tons $\mathrm{km}^{-2}$. (Stelfox et al. 1980). These herbivores consume at least $30 \%$ of the total annual aboveground net primary production (Stelfox et al. 1980). The most important species on a biomass basis included Connochaetes taurinus (wildebeest), Equus burchelli (zebra), Syncerus caffer (buffalo), Damaliscus korrigum (topi), Giraffa camelopardalis (giraffe), and Loxodonta africana (elephant). More detailed information on this ecosystem can be found in Sinclair and Norton-Griffiths (1979).

Canopy reflectance at 0.800 and $0.675 \mu \mathrm{m}$ was measured with a Tektronix portable radiometer on $580.25-\mathrm{m}^{2}$ plots in the eastern half of Masai Mara Game Reserve between July 26 and 28, 1980. These plots were randomly arranged within 15 study sites where studies assessing annual biomass dynamics were in progress. These study sites were initially chosen so that all grassland types in the eastern half of the game reserve were represented. The probes of the radiometer were held approximately $1.2 \mathrm{~m}$ above the surface of a plot to be measured, giving an effective viewing area of $0.25-\mathrm{m}^{2}$. Most readings were taken between 0900 and 1500 hours, although some were taken as early as 0645 and as late as 1600 . Readings were taken irrespective of atmospheric conditions or substrate color. The sun was intermittently obscured by clouds on both days on which reflectance readings were taken.

After obtaining reflectance measurements, each plot was assessed for species composition, cover, grazing intensity, and then clipped to ground level. Plant material was separated into litter, grass, forb, and sedge categories in the field. Each category (except litter) was then separated into green and dead components in the lab. All vegetation was dried at $80^{\circ} \mathrm{C}$ for 48 hours and then weighed to the nearest 0.1 gram. Regression and correlation analyses were then employed to assess relationships among the variables and to assess the predictive value of reflectance ratio as an estimator of green biomass.

In order to assess the ability of the radiometer to measure reflectance from lower leaf layers in dense canopies, 4 plots of high total biomass were clipped in a stratified manner. Spectroreflectance measurements were taken in each plot before clipping all biomass above $100,80,60,40$, and $20 \mathrm{~cm}$. In addition, spectroreflectance was measured after all standing biomass was removed and only litter remained, and again after litter was removed. Thus, 7 measurements were made on each of 4 plots.

Four additional plots were selected to test the effect of time of day on spectroreflectance values. Each plot was measured at approximately hourly intervals from 0645 to 1600 hours, after 
Table 1. Correlation coefficients among the variables. An * indicates significance at the .05 level. $N=58$ for all correlations.

\begin{tabular}{lcccccc}
\hline \hline & $\begin{array}{c}\text { Reflec- } \\
\text { tance } \\
\text { ratiol }\end{array}$ & $\begin{array}{c}\text { Total } \\
\text { green }\end{array}$ & $\begin{array}{c}\text { Green } \\
\text { grass }\end{array}$ & $\begin{array}{c}\text { Green } \\
\text { forb }\end{array}$ & $\begin{array}{l}\text { Green } \\
\text { sedge }\end{array}$ & $\begin{array}{c}\text { Total } \\
\text { dead }\end{array}$ \\
\hline Total green & $0.84^{*}$ & & & & & \\
Green grass & $0.82^{*}$ & $0.99^{*}$ & & & & \\
Green forb & 0.20 & 0.22 & 0.10 & & & \\
Green sedge & 0.07 & -0.02 & -0.11 & -0.09 & & \\
Total dead & 0.13 & 0.20 & 0.19 & $0.33^{*}$ & -0.24 & \\
Litter & -0.24 & -0.20 & -0.16 & -0.01 & $-0.37^{*}$ & $0.45^{*}$ \\
\hline
\end{tabular}

Defined as canopy reflectance at $.800 \mu \mathrm{m}$ divided by reflectance at $.675 \mu \mathrm{m}$

which time the plots were clipped as described above.

\section{Results}

The 58 plots sampled in this study had an average of 5 species per $0.25-\mathrm{m}^{2}$ plot (range $=2-10$ ). Standing crop (live plus dead) ranged from $18 \mathrm{~g}^{-2}$ to $588 \mathrm{~g}^{-2}$. Grasses composed $94 \%$ of the total biomass, forbs $2 \%$, and sedges $4 \%$. The percentage of live material in the standing crop ranged from $6.8 \%$ to $74.3 \%$ (mean $=54 \%$ ).

Correlations between the vegetation categories were generally weak (Table 1). The strong relationship between green grass and total green biomass was expected since $94 \%$ of the total green biomass was grass. The reflectance ratio showed significant correlations with total green biomass and with green grass biomass, suggesting that the ratio could be used as a predictor of green biomass.

Regression analysis showed that reflectance ratio is a predictor of total green biomass (Fig. 1), accounting for a significant proportion of the variation of biomass values $\left(r^{2}=70 \%, P<.001\right)$. It should be noted that the standard error of the estimate is large ( 38.6 $\mathrm{g} \cdot \mathrm{m}^{-2}$ or $386 \mathrm{~kg}^{\circ} \mathrm{ha}^{-1}$ ) when the reflectance ratio is used to predict the dry weight of green biomass (Fig. 1). Standing crop (live plus dead) is also significantly correlated with reflectance ratio, but predictability is much lower $\left(r^{2}=25 \%\right)$. There is no evidence from our results that the a mount of biomass present in the plots was high enough to require a nonlinear predictive equation (Tucker 1977).

Some of the scatter about the regression line in Figure 1 may be explained by Figure 2 . When the average percent errors of the biomass values predicted by the equation in Figure 1 are plotted against the proportion of live biomass, it is clear that error becomes unacceptable in plots having less than about $30 \%$ live biomass.

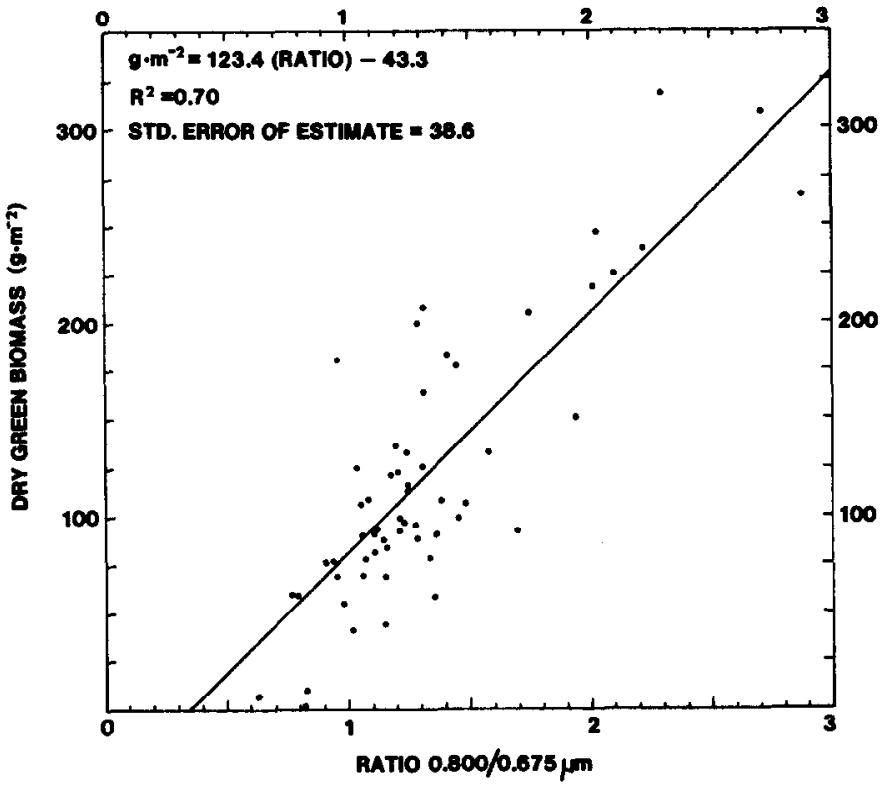

Fig. 1. Relationship between reflectance ratio $(.800 / .675 \mu \mathrm{m})$ and dry weight of green biomass $(N=58)$.

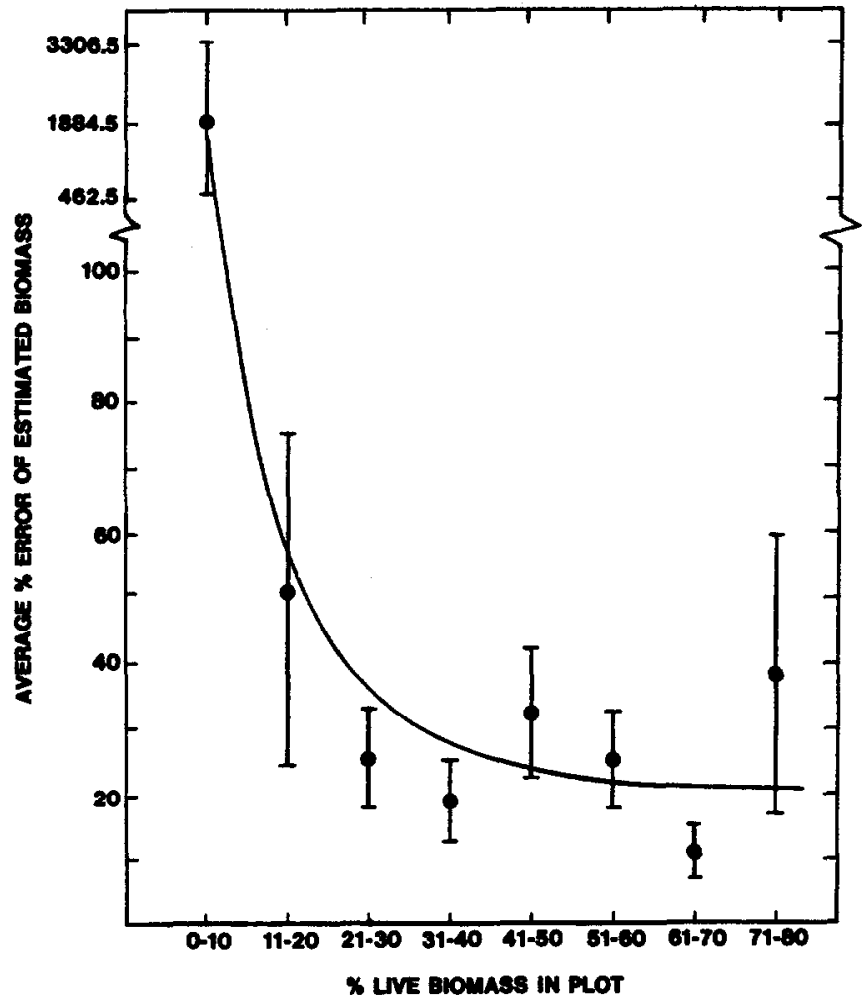

Fig. 2. Percent error of the estimates from the equation in Figure 1 as a function of the proportion of live vegetation. Vertical bars are standard errors of the means.

This same result has been obtained by other investigators (Pearson et al. 1976). Nineteen of the points in Figure 1 are from plots having less than $30 \%$ live vegetation, and undoubtedly represent much of the variation unaccounted for by the regression. In plots with more than $30 \%$ live biomass, error of estimates is still substantial (10-30\%), but much smaller than plots with a lower proportion of live biomass (Fig. 2).

Results from the 4 plots clipped in a stratified manner are shown in Figure 3. These data indicate that the radiometer predicts biomass from tall, dense canopies as well as from lower canopies, at least within the range of biomass values encountered in this study. Slopes of regression lines in Figure 3 are significantly different from the regression line in Figure $1(P<0.001)$. This could be due to

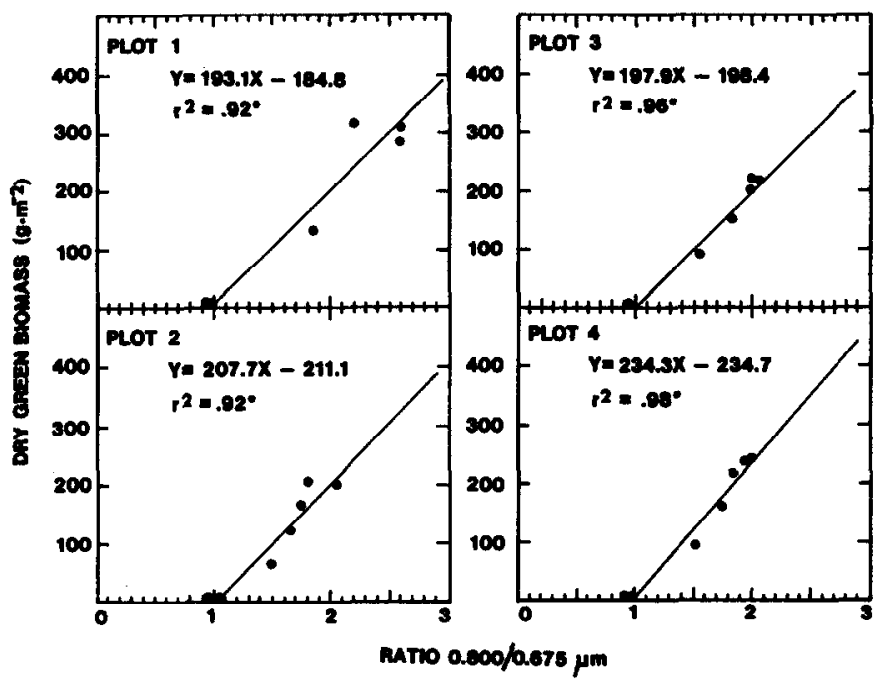

Fig. 3. Results of reflectance measurements made on plots clipped in a stratified manner. S.E. EST. is the standard error of the estimate. 


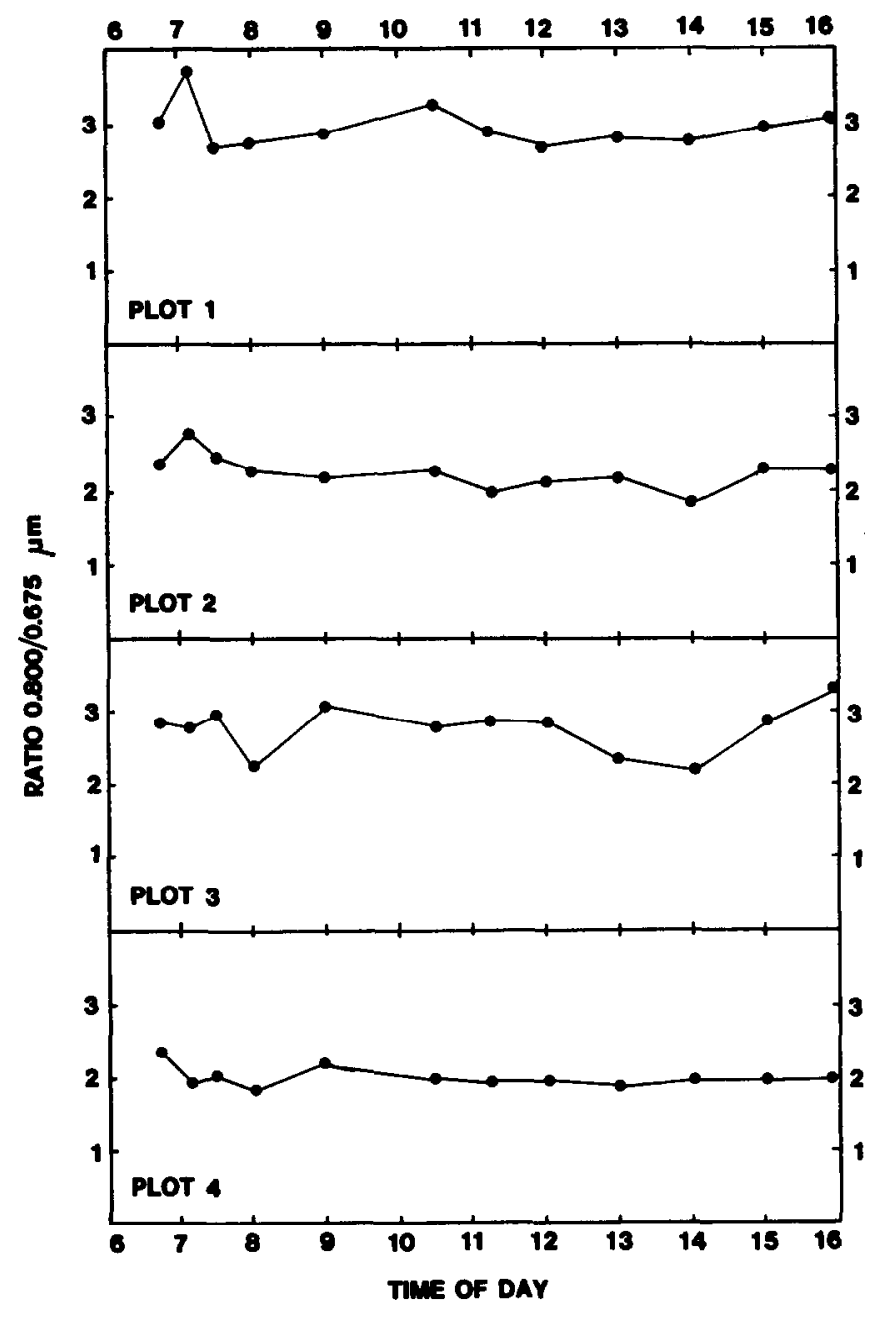

Fig. 4. Effect of time of day on canopy spectral reflectance values of four replicate plots.

reduced variability of cloud cover, substrate color, time of day, and percentage of live biomass encountered while collecting the data in Figure 3 compared with conditions encountered while collecting data for Figure 1. All of these variables have been shown to influence spectral reflectance from plant canopies (Colwell 1974, Tucker 1980).

Based on the data from the 4 plots that were measured repeatedly during the course of an entire day, it appears that spectral reflectance measurements made between 1000 and 1400 hours are less variable than those taken at other times of day (Fig. 4). Furthermore, spectroreflectance measurements taken between 1000 and 1400 hours are somewhat less prone to prediction error than measurements at other times of day (Fig. 5). However, analysis of variance shows that estimation errors for measurements taken between the times of 0600-1000, 1000-1400, and 1400-1600 hours are not significantly different from each other $(P>.05)$.

\section{Discussion}

The results of this study show that canopy spectroreflectance measurements at 0.800 and $0.675 \mu \mathrm{m}$ in the open grasslands of Masai Mara Game Reserve can be useful as estimators of green biomass. Linked with the presently routine animal surveys in this area (Stelfox et al. 1980), these measurements could help provide a greater understanding of the properties of this ecosystem.

Between 1961 and 1979, the population of wild herbivore species in this area has increased by a factor of 5 , and most species continue to have a high rate of increase (Stelfox et al. 1980). Effective study and management of these animals in relation to their resource

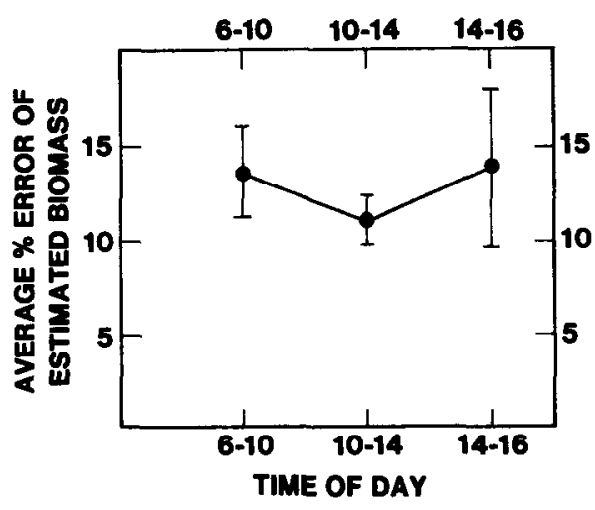

Fig. 5. Percent error of biomass estimates in Figure 4 as a function of time of day measurements were made. Vertical bars are standard errors of the means.

requirements necessitates a routine assessment of vegetation availability on a spatial and temporal basis. The spectral reflectance technique appears to be a suitable alternative to other more timeconsuming methods and appears suitable for either ground or aerial measurements (McNaughton 1979, Pearson et al. 1976).

Our results are similar to those of McNaughton (1979) for the adjacent Serengeti National Park in Tanzania. His predictive equation accounted for a higher proportion of the variation in biomass values $\left(r^{2}=96 \%\right.$ vs. our $70 \%$ ), but this could be due to the fact that none of his calibration plots contained less than $36 \%$ live biomass. Nineteen of our 58 plots contained less than $30 \%$ live vegetation. As shown in Figure 2, error of estimation increases drastically as the percentage of live biomass falls below $30 \%$. Intense herbivory, frequent fires, and a favorable rainfall regime maintain plant standing crop near or above $50 \%$ live during most of the year at Masai Mara (our unpublished data). Thus, a high proportion of standing dead would not be a regular hindrance to spectral reflectance studies in this region. Efforts to use spectral reflectance in more xeric grasslands in Kenya where the percentage of live biomass is consistently low have been less successful (Croze et al. 1978, Gwynne 1977), accounting for only 23 to $38 \%$ of the variation in biomass values, depending on whether data were transformed or not.

The standard error of the estimate of our predictive equation (Fig. 1) is $38.6 \mathrm{~g}^{-2}$ or $386 \mathrm{~kg}^{-1} \mathrm{ha}^{-1}$. This would be a significant source of error in investigations requiring precise measurements, such as productivity studies. However, this error would be less important for gross surveys of green biomass, for detecting large seasonal differences in biomass, or, in this ecosystem, for estimating consumption by large herbivores during annual migratory periods.

We suggest that it should be possible to improve the predictive value of spectral reflectance measurements. First, our data show a trend towards less error in measurements taken within 2 hours of noon (Fig. 5). Although this trend in our data is not statistically significant, other investigators have reported that error from solar zenith angle can be important (Tucker 1980). Second, our measurements were made irrespective of atmospheric conditions; some measurements were made under cloudless conditions, while others were made when the sun was obscured by clouds. Tucker (1980) reports that measurements obtained under cloud-free conditions may not be directly comparable with measurements taken under overcast conditions. One could conceivably develop a predictive equation for use on cloudy days and a separate equation for clear days. Alternatively, Waller et al. (1981) have had some success with minimizing both the influence of time of day and cloud cover by use of a calibration panel.

In summary, we have found that reflectance ratios $(.800 / .675$ $\mu \mathrm{m})$ obtained from plant canopies in an East African grassland are reliable predictors of green biomass. The method clearly has potential for monitoring spatial and temporal variability of plant biomass and could be used as a means of studying the relationship 
between herb layer vegetation and the rapidly increasing herbivore populations in this region. This kind of information would be most useful in implementing effective management policies in the Masai Mara Game Reserve.

\section{Literature Cited}

Colwell, J. 1974. Vegetation canopy reflectance. Remote Sens. Environ. $3: 175-183$.

Croze, H., P. Mumuikha, H. Mbai, and M. Owaga. 1978. Estimates of grazer food supply and demand in the Athi-Kapiti ecosystem of Kajiado District, Kenya. U.N.D.P./F.A.O. Wildl. Manage. Proj. Working Document No. 17.

Gwynne, M.D. 1977. Landsat image studies of green flush events in Kajiado District, Kenya. U.N.D.P./F.A.O. Wildl. Manage. Proj. Working Document No. 15.

McNaughton, S.J. 1976. Serengeti migratory wildebeest: facilitation of energy flow by grazing. Science. 191:92-94.

McNaughton, S.J. 1979. Grassland-herbivore dynamics. In: Serengeti: Dynamics of an ecosystem, A.R.E. Sinclair and M. Norton-Griffiths (eds.). Univ. of Chicago Press, Chicago.
Pearson, R., C. Tucker, and L. Miller. 1976. Spectral mapping of shortgrass prairie biomass. Photogramm. Eng. and Remote Sens. 42:317-323.

Sinclair, A.R.A, and M. Norton-Griffiths (eds.). 1979. Serengeti: Dynamics of an ecosystem. Univ. Chicago Press, Chicago.

Stelfox, J., D. Peden, S. Mbugua, C. Amuyuryu, and R. Hudson. 1980. Populations, stocking rates, and distributions of wild life and livestock on Mara and Loita Plains: December 1978-November 1979. Kenya Rangeland Ecological Monitoring Unit Tech. Rep. Ser. 19:1-72.

Taiti, S.W. 1973. A vegetation survey of the Masai Mara Game Reserve, Narok District, Kenya. M. Sc. thesis, University of Nairobi, Kenya.

Tucker, C.J. 1977. Asymptotic nature of grass canopy spectral reflectance. Appl. Optics. 16:1151-1156.

Tucker, C.J. 1977. Spectral estimation of grass canopy variables. Remote Sens. Environ. 6:11-26.

Tucker, C.J. 1980. A critical review of remote sensing and other methods for non-destructive estimation of standing crop biomass. Grass and Forage Sci. 35:177-182,

Waller, S.S., M.A. Brown, and J.K. Lewis, 1981. Factors involved in estimating green biomass by ca nopy spectroreflectance measurements. $J$. Range Manage. 34:105-108.

\title{
RANGELAND HYDROLOGY
}

\author{
by Farrel A. Branson, Gerald F. Gifford, Kenneth G. Renard, and \\ Richard F. Hadley
}

Unique in its emphasis on the hydrology of rangelands, primarily arid and semiarid lands, RANGELAND HYDROLOGY provides a text for one aspect of range management where none has existed before. This expanded Second Edition presents in-depth information for those who must manage rangeland or respond to questions about the impacts of land use practices on hydrology.

Included in the new Second Edition are a chapter on modeling with approaches to predicting the effects of land use, and a chapter on the rapidly developing field of snow pack management.

The 352-pages include 197 illustrations, providing rapid access to an assembly of data found nowhere else and useful in the preparation of environmental impact statements. Extensive bibliographic material with each chapter and a subject matter index add to the useableness of the book.

Range scientists and managers, soil conservationists, hydrologists, agricultural engineers, land reclamation specialists, wildlife managers, graduate and undergraduate students and their professors, as well as all interested in the hydrology of arid lands will find RANGELAND HYDROLOGY a valuable addition to their libraries. (352 pages paper laminated cover $\$ 15.00$ US) 